\title{
Density currents as a desert dust mobilization mechanism
}

\author{
S. Solomos ${ }^{1}$, G. Kallos $^{1}$, E. Mavromatidis ${ }^{1,2}$, and J. Kushta ${ }^{1}$ \\ ${ }^{1}$ University of Athens, School of Physics, University of Athens Campus, Bldg. Phys-5, 15784 Athens, Greece \\ ${ }^{2}$ Ministry of Education/Higher Education Division, Athens, Greece \\ Correspondence to: G. Kallos (kallos@mg.uoa.gr)
}

Received: 30 July 2012 - Published in Atmos. Chem. Phys. Discuss.: 22 August 2012

Revised: 19 October 2012 - Accepted: 20 November 2012 - Published: 27 November 2012

\begin{abstract}
The formation and propagation of density currents are well studied processes in fluid dynamics with many applications in other science fields. In the atmosphere, density currents are usually meso- $\beta / \gamma$ phenomena and are often associated with storm downdrafts. These storms are responsible for the formation of severe dust episodes (haboobs) over desert areas. In the present study, the formation of a convective cool pool and the associated dust mobilization are examined for a representative event over the western part of Sahara desert. The physical processes involved in the mobilization of dust are described with the use of the integrated atmospheric-air quality RAMS/ICLAMS model. Dust is effectively produced due to the development of near surface vortices and increased turbulent mixing along the frontal line. Increased dust emissions and recirculation of the elevated particles inside the head of the density current result in the formation of a moving "dust wall". Transport of the dust particles in higher layers - outside of the density current - occurs mainly in three ways: (1) Uplifting of preexisting dust over the frontal line with the aid of the strong updraft (2) Entrainment at the upper part of the density current head due to turbulent mixing (3) Vertical mixing after the dilution of the system. The role of the dust in the associated convective cloud system was found to be limited. Proper representation of convective processes and dust mobilization requires the use of high resolution (cloud resolving) model configuration and online parameterization of dust production. Haboob-type dust storms are effective dust sources and should be treated accordingly in dust modeling applications.
\end{abstract}

\section{Introduction}

The role of mineral dust on regional and global atmospheric processes is important in many aspects. Various studies have shown that dust particles change the optical properties of the atmosphere and redistribute the radiative fluxes (Myhre et al., 2003; Seinfeld et al., 2004; IPCC, 2007; Ramanathan et al., 2007). They can also serve as cloud condensation nuclei $(\mathrm{CCN})$, gigantic cloud condensation nuclei $(\mathrm{GCCN})$ and ice nuclei (IN), thus changing the radiative and microphysical properties of the clouds and also the precipitation patterns (Levin et al., 1996; Givati and Rosenfeld, 2004; Solomos et al., 2011). Parameterization of dust mobilization, based on soil properties and friction velocity, is included in several numerical models (i.e. Marticorena et al., 1997; Zender et al., 2003; Spyrou et al., 2010; Solomos et al., 2011). However, the number of studies on the role of other local scale meteorological features that can trigger dust episodes, such as density currents, is still limited.

Density currents are generally produced from the downdrafts of convective storms and are related to significant changes in several atmospheric properties. The passage of a density current is usually associated with a pressure rise, a shift in wind direction, and an increase in wind speed (Knippertz et al., 2007; Miller et al., 2008; Emmel et al., 2010). This combination can lead to boundary layer convergence. The warm and moist air in the lower tropospheric levels is lifted above the wedge of cool air and a line of severe but shallow convection occurs above the surface intrusion (Carbone, 1981; Chimonas and Kallos, 1985). As described in Knippertz et al. (2003), the passage of an upper level trough over Eastern Atlantic can cause enough atmospheric instability and produce significant amounts of convective precipitation over the Atlas Mountains. The evaporation of the rain 
droplets in the lower levels of the atmosphere, leads to a decrease in air temperature thus creating a cool pool. Similar systems are also associated with the generation of downdrafts due to tropical convection as described in Bou Karam et al. (2008).

Mobilization of dust due to density currents is a common feature for many regions in Africa (Schepanski et al., 2009; Emmel et al., 2010). These systems can be produced either from deep convection in the tropics or from orographic storm activity over the Atlas Mountains (Sutton, 1925; Lawson, 1971; Knippertz et al., 2007). The generated dust fronts, like the haboobs of Sudan, have lifetimes of several hours and horizontal extension that can reach several hundreds of kilometers (Sutton, 1925; Lawson, 1971; Hastenrath, 1991). Several density current formations were observed during the Saharan Mineral Dust Experiment (SAMUM) that took place on May and June 2006 over NW Africa and are described by Knippetz et al. (2007). As reported in their work, eight density current systems were identified over the area of Atlas Mountains between 11 May and 10 June 2006. The climatology of these formations is described by Emmel et al. (2010) based on in-situ observations for the period 2002-2006. The high frequency of the phenomena indicates the need for a more accurate representation of this mechanism in dust models. Until now, there is little knowledge about the physical processes involved in the production of dust through this mechanism (Marsham et al., 2011) and only a few modeling studies have been presented on this subject. This is mainly due to the lack of sufficient observational data over arid areas and also because of the relatively coarse resolution of dust models that is not appropriate for resolving such small scale features.

Estimating the dust emissions in numerical models is a complex task since the dust fluxes are affected by both surface and atmospheric properties. For example, parameterizing the seasonal variability of land use (Tegen et al., 2004) or parameterizing the sub-grid wind speed variability (Cakmur et al., 2004) has been found to improve the representation of dust in atmospheric models. Describing the dust fluxes becomes even harder in areas where convective activity is frequent (e.g. NW Sahara, Ethiopian Plateau, Arabian Peninsula, Sahel and USA). In such areas, dust production and transportation is often driven by convective storm outflows (Membery, 1985; Hastenrath, 1991; Chen and Fryrear, 2002). These "haboob" dust storms may occur during both day and night and although observational studies report a significant frequency of appearance (Marticorena et al., 2010), this phenomenon has not been yet extensively studied in dust-modeling experiments. The existing convective parameterization schemes are not adequate to describe such processes, therefore the convective downdrafts and the associated dust fronts need to be explicitly resolved in numerical simulations (Marsham et al., 2011). Recently, Knippertz et al. (2009) presented a modeling study on density current formation over NW Africa using the COSMO model (Step- peler et al., 2003), without including a parameterization for the dust mobilization mechanism. In another study, Reinfried et al. (2009) used an offline version of the dust emission scheme in LM-MUSCAT (Heinold et al., 2007) to describe dust fluxes over the same area. Takemi (2005) described the primary mechanisms of mineral dust elevation in density currents for Gobi desert, using idealized simulations of a squall line for a simplified modeling domain. Seigel and van den Heever (2012) used idealized model simulations of a supercell thunderstorm to examine the uplifting and ingestion of dust for an already dusty atmosphere and for an initially dustfree environment.

The main objective of this study is to describe the processes that lead to dust production during the passage of a density current. For this purpose, several cases have been analyzed in Africa and the Middle East and a characteristic case in NW Africa has been selected for detailed description. All the simulated cases exhibited similar behavior. As stated also in Knippertz et al. (2007) this particular case is a good example of haboob formation in the area mainly due to the isolated nature of the density current which allows a more in depth examination of its main properties. The production of dust due to convective outflow was simulated with the use of a directly coupled atmospheric-air quality model. High resolution simulations were performed for the description of the small scale physical processes related to the convective downdrafts and the associated mobilization of dust particles. The intensity and structure of the generated density current and the accompanying dust front are discussed based on model results and observations.

The paper is organized as follows: a short description of the model characteristics are presented in section two. In section three, experimental simulations are analyzed and the modeling results are compared to available observational data. Section four contains some concluding remarks concerning the role of density currents in dust production.

\section{Model description and set-up}

For the current study the RAMS/ICLAMS model was used (Solomos at al., 2011). The model is an enhanced version of the Regional Atmospheric Modeling System (RAMS6.0) (Pielke et al., 1992; Meyers et al., 1997; Cotton et al., 2003). The modeling features include: (1) Two-way nesting (2) Dust and sea-salt mechanisms that are online coupled with meteorology (3) Cloud droplet nucleation and ice formation based on atmospheric composition (activation of airborne particles as CCN, GCCN and IN) (4) Online gas and aqueous phase chemistry (5) Heterogeneous chemical processes (6) Interactive radiation scheme that takes into account the effects of atmospheric composition on radiative transfer.

The online dust production scheme is based on the saltation and bombardment hypothesis following the $u_{*}$ threshold parameterization (Marticorena and Bergametti, 1995; Spyrou 


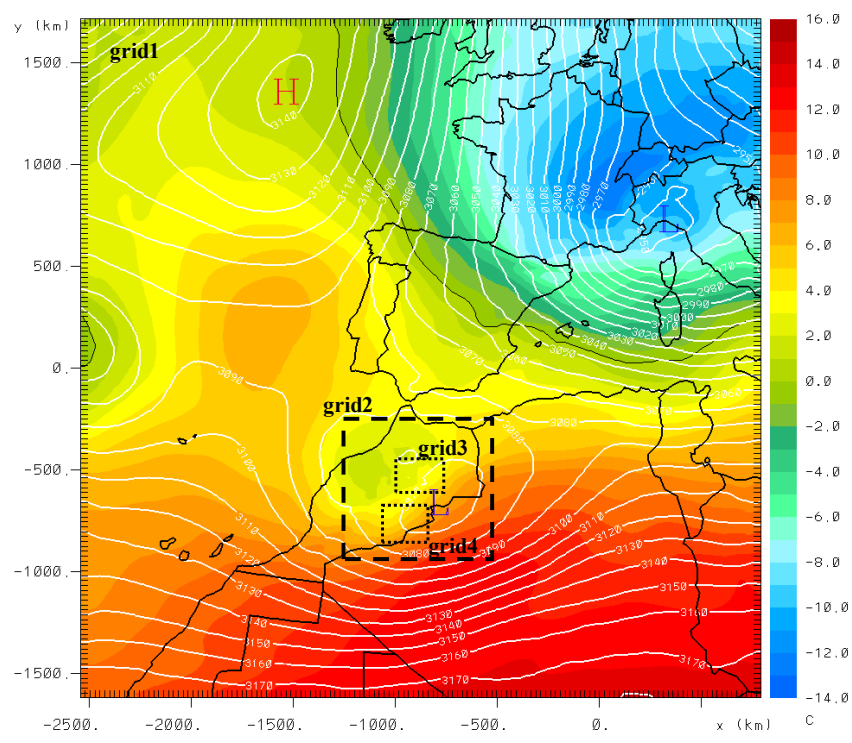

Fig. 1. Geopotential height (white contour lines every $10 \mathrm{gpm}$ ) and temperature at $700 \mathrm{hPa}$ (color palette in ${ }^{\circ} \mathrm{C}$ ) - 11:00 UTC on 31 May 2006. The dashed rectangulars indicate the locations of the nested grids.

et al., 2010). The saltation flux depends on the excess of wind friction velocity over the threshold speed for the entrainment of dust particles. Dust production depends on friction velocity and on the efficiency with which drag is partitioned between erodible and non-erodible soil. The effects of rain on soil moisture and the related reduction of dust production is explicitly treated based on the parameterization of Fécan et al. (1999). The vertical dust flux is then distributed into three lognormal source modes with different shapes and mass fractions (Zender et al., 2003). The transport mode is represented by eight size bins with effective radius of $0.15,0.25,0.45$, $0.78,1.3,2.2,3.8$ and $7.1 \mu \mathrm{m}$. The model includes full parameterization of dry deposition processes as well as inside and below-cloud scavenging of the particles following the formulation of Seinfeld and Pandis (1998). The prognostic aerosol particles are treated as predictive quantities in the explicit microphysics scheme for the calculations of $\mathrm{CCN}$ and IN activation following the formulations of Fountoukis and Nenes (2005) and Barahona and Nenes (2009).

The experimental domain for the selected case was configured with four grids: a parent grid of $12 \times 12 \mathrm{~km}$ horizontal resolution and three two-way interactive nested grids as illustrated in Fig. 1. The resolution of the intermediate grid was $2.4 \times 2.4 \mathrm{~km}$ and the resolution of the two finest grids was $800 \times 800 \mathrm{~m}$. In the vertical grid, a total of 44 model layers were used. The vertical coordinates were hybrid terrain following $\sigma_{z}$, starting with a resolution of $20 \mathrm{~m}$ near the ground and stretching up to $18 \mathrm{~km}$ with a factor of 1.10 . This configuration results in 23 model layers from the surface up to $3 \mathrm{~km}$ in the atmosphere and allows for adequate representation of the lower tropospheric structure, convection and tur- bulence motions. Surface elevation was retrieved from the global USGS topography dataset at $3^{\prime \prime} \times 3^{\prime \prime}$ resolution. The ECMWF $0.5^{\circ} \times 0.5^{\circ}$ objective analysis fields were used for initial and lateral boundary conditions. The sea surface temperature (SST) is the NCEP $0.5^{\circ} \times 0.5^{\circ}$ analysis data. The Kain-Fritsch (Kain and Fritsch, 1993) convective parameterization scheme was activated for the outer grid and the RRTMG radiative transfer scheme (Mlawer et al., 1997; Iacono et al., 2000) was used for both shortwave and longwave bands on all grids. For all simulations, dust was treated as a prognostic quantity in radiative transfer calculations. For the intermediate and finest model grids no convective parameterization was used and convection was resolved by the explicit microphysics scheme of the model.

\section{Mobilization of dust particles in the Atlas region}

During 31 May 2006 a low-pressure system was located over Morocco and southern Spain as shown in Fig. 1. The trough passage and the existence of cold air at upper levels enforced convection and intense rainfall over the Atlas Mountains during the afternoon hours of 31 May 2006. As seen in both TRMM satellite retrievals in Fig. 2a and model output in Fig. 2b, these convective clouds produced significant amounts of 24-h accumulated precipitation exceeding $25-30 \mathrm{~mm}$ over the area south of the Atlas Mountains. At 15:00 UTC, the station of Errachidia $\left(31.93^{\circ} \mathrm{N}, 4.40^{\circ} \mathrm{W}\right)$ reported a thunderstorm and a drop in temperature of about $10^{\circ} \mathrm{C}$. The simulated rainfall rate at the same station reached $11 \mathrm{~mm} \mathrm{~h}^{-1}$ at 14:00 UTC and as seen also in Fig. 2c it was accompanied by a drop in temperature of about $12-14^{\circ} \mathrm{C}$. These conditions favor the development of storm downdrafts due to evaporative cooling. As the raindrops fall through a warmer and unsaturated environment, some of them evaporate before reaching the ground. Absorption of the vaporization latent heat results in decrease of the ambient temperature and the cooler air falls to the ground.

The formation of a cool pool south of the Atlas Mountains resulted in the development of a fast propagating density current. The steep topographic slope enhanced propagation and the system moved southwards towards the Morocco-Algeria borderline accompanied by dust production and by a squall line of shallow convective clouds as seen in Fig. 3. Modeling output was compared to satellite observations from the Meteosat Second Generation (MSG) Spinning Enhanced Visible and InfraRed Imager (SEVIRI) (Schmetz et al., 2002). These images are available online by EUMETSAT (http: //www.eumetsat.int). Both model results and satellite observations from the MSG/SEVIRI dust indicator system showed an extended frontal line of about $300 \mathrm{~km}$ that was associated with intense dust production and cloud cover.

The gravity current propagation speed can be theoretically approximated using a simple expression (von Karman, 1940; Carbone, 1981): 

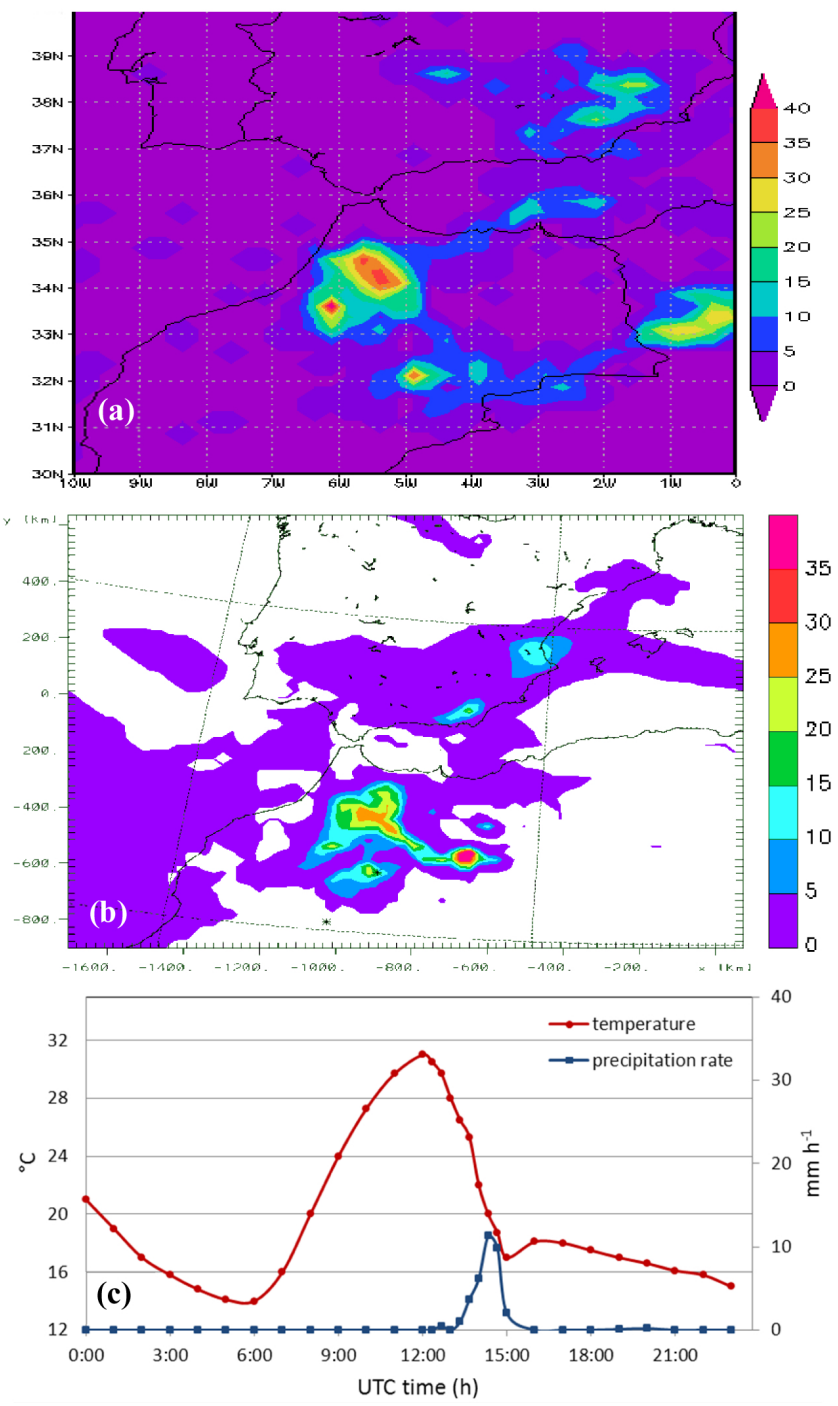

Fig. 2. (a) Satellite retrieval of $24 \mathrm{~h}$ accumulated precipitation ( $\mathrm{mm}$ ) from the Tropical Rainfall Measuring Mission (TRMM - http:// trmm-fc.gsfc.nasa.gov/trmm_gv). (b) Model output of $24 \mathrm{~h}$ accumulated precipitation $(\mathrm{mm})$. (c) Modeled precipitation rate $\left(\mathrm{mm} \mathrm{h}^{-1}\right)$ and temperature $\left({ }^{\circ} \mathrm{C}\right)$ at the station of Errachidia on 31 May 2006. The drop in temperature between 12:00-15:00 UTC indicates the formation of a cool pool due to the evaporation of rain droplets.

$V=2\left(g \Delta z \frac{T_{\mathrm{v} 1}-T_{\mathrm{v} 2}}{T_{\mathrm{v} 2}}\right)^{\frac{1}{2}}$

In this equation $g=9.81 \mathrm{~m} \mathrm{~s}^{-2}$ is the gravitational acceleration, $\Delta z$ is the depth of the current and $T$ is the virtual temperature of the lighter $\left(T_{\mathrm{v} 1}\right)$ and the denser $\left(T_{\mathrm{v} 2}\right)$ air mass. For an average modeled depth of $2 \mathrm{~km}, T_{\mathrm{v} 1}=310 \mathrm{~K}$ and $T_{\mathrm{v} 2}=309 \mathrm{~K}$, (1) yields $V=11.2 \mathrm{~m} \mathrm{~s}^{-1}$. The modeled propagation speed did not change significantly during the simulation period. As seen in Fig. 4, the leading edge of the system
- which was also the area of increased dust mobilization can be clearly defined by the isotach of $11 \mathrm{~m} \mathrm{~s}^{-1}$.

\subsection{Dynamics of the density current and dust production}

The process of the density current formation is evident at the North-South cross-section of rain mixing ratio and potential temperature from the third model grid (Fig. 5a). The generation of the cool pool is indicated by the "dome" of the isentropes inside and ahead of the precipitating area. The vertical orientation of the $307 \mathrm{~K}$ isentropic contour line indicates the leading edge of the propagating front. The process of evaporative cooling is evident in Fig. $5 \mathrm{~b}$ by the decrease in equivalent potential temperature $\left(\theta_{\mathrm{e}}\right)$. Close to the surface and inside the precipitating area $\theta_{\mathrm{e}}$ was as low as $337 \mathrm{~K}$. The cool pool intrusion produced a region of intense updrafts ahead of the front that are indicated with black line contours in Fig. 5c. Vertical wind speed at the leading edge of the system often exceeded $4 \mathrm{~m} \mathrm{~s}^{-1}$, while the horizontal wind component within the propagating system ranged between $11-24 \mathrm{~m} \mathrm{~s}^{-1}$ as seen in Fig. 5c.

The pre-frontal and post-frontal vertical wind profiles were computed for a specific location $\left(31.82^{\circ} \mathrm{N},-4.39^{\circ} \mathrm{W}\right)$ that is about $20 \mathrm{~km}$ south of the area where the cool pool was generated in the model. The system approached this location at 12:50 UTC and the profiles were taken every ten minutes (12:20-13:20 UTC). As shown in Fig. 6a, b, the abrupt change in wind velocity at $2.5 \mathrm{~km}$ indicates the depth of the turbulent layer. The wind speed inside this layer reached $12 \mathrm{~m} \mathrm{~s}^{-1}$ at 12:50 UTC during the passage of the front. Before the arrival of the front there was no vertical wind shear and a uniform NNE flow was found within the lower $2.5 \mathrm{~km}$ in the atmosphere (Fig. 6b). After 12:50 UTC a gradual anticyclonic veering was evident and the winds turned from NNE at the surface to WSW above $3 \mathrm{~km}$. The impact of these specific conditions on dust production can be possibly examined with regards to the flow structure inside the propagating system. Due to the increased wind shear the horizontal components $\xi=\boldsymbol{i}\left(\frac{\partial w}{\partial y}-\frac{\partial v}{\partial z}\right)$ and $\eta=\boldsymbol{j}\left(\frac{\partial u}{\partial z}-\frac{\partial w}{\partial x}\right)$ in the relative vorticity Eq. (2), obtained significant values during the episode.

$J=\boldsymbol{\nabla} \times \boldsymbol{V}=\boldsymbol{i}\left(\frac{\partial w}{\partial y}-\frac{\partial v}{\partial z}\right)+\boldsymbol{j}\left(\frac{\partial u}{\partial z}-\frac{\partial w}{\partial x}\right)+\boldsymbol{k}\left(\frac{\partial v}{\partial x}-\frac{\partial u}{\partial y}\right)$

In this equation $\boldsymbol{i}$ heads to the east, $\boldsymbol{j}$ heads to the north and $\boldsymbol{k}$ is perpendicular to the plane defined by $\boldsymbol{i}$ and $\boldsymbol{j}$ with upward direction. As seen in Fig. 6c, the $\xi$ relative vorticity component along the WE-axis (axis parallel to the rainband) was positive close to the surface at the pre-frontal environment (12:20-12:30 UTC) and became negative during the passage of the system. The minimum value of $\xi$ was $-1.2 \times 10^{-2} \mathrm{~s}^{-1}$ at 12:50 UTC. The $\eta$ relative vorticity component along the NS-axis (perpendicular to the rainband) was also negative at 12:50 as seen in Fig. 6d. Due to the friction at the lower boundary, two distinct flow areas were formed inside the 

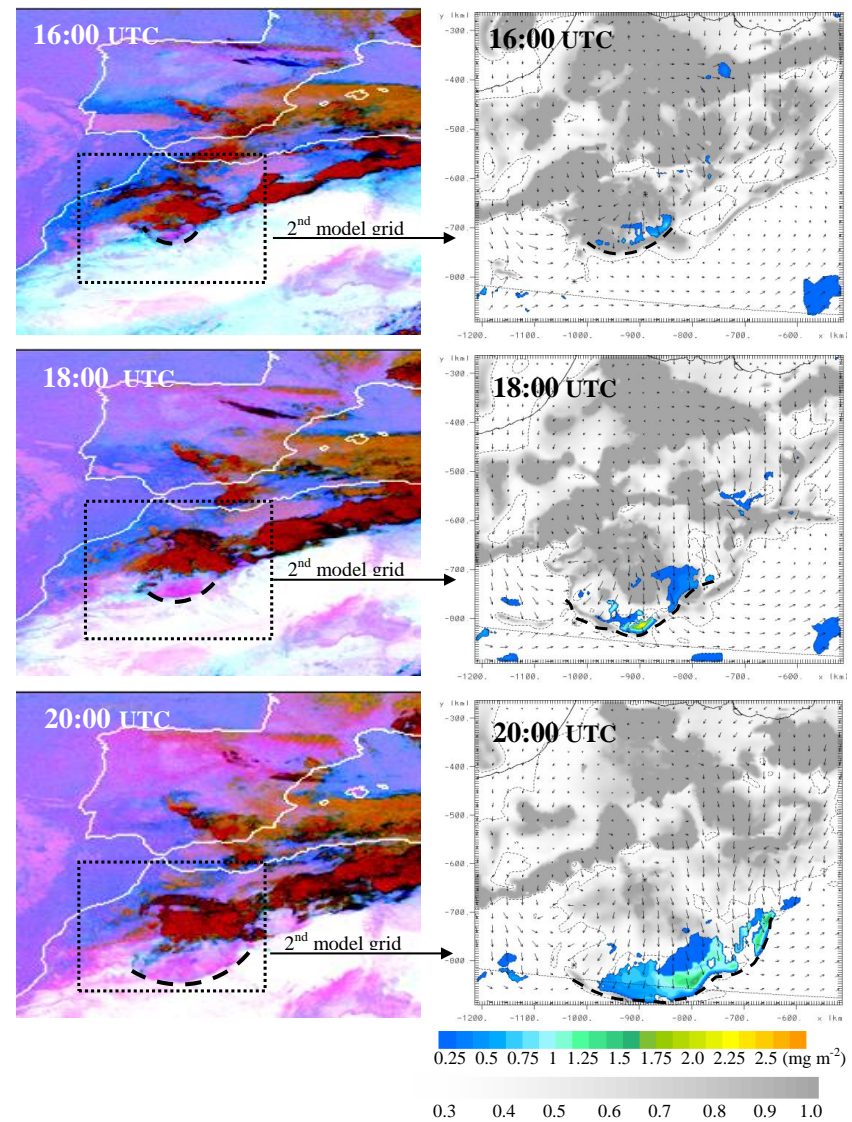

Fig. 3. Left column: MSG/SEVIRI dust indicator satellite images over North West Africa. Dark red colors indicate clouds and purple colors indicate desert dust. Right column: corresponding model cloud fraction (grayscale) and dust production (color palette in $\mathrm{mg} \mathrm{m}^{-2}$ /model timestep). The leading edge of the propagating density current is denoted with black dashed lines.

propagating head similar to earlier findings from relevant studies (e.g. Simpson, 1972; Carbone, 1983). This change in the flow structure is evident in the WE cross-section of Fig. 7. In this figure the black dashed line indicates the area of zero $\xi$ and the arrival of the density current head is defined by the contours of wind speed reaching $12 \mathrm{~m} \mathrm{~s}^{-1}$ in the core of the system. The $\xi$ vorticity component retained positive values in the pre-frontal atmosphere (before 12:50 UTC). At 12:50 UTC $\xi$ became negative for a vertical area extending from $200 \mathrm{~m}$ above surface up to the top of the approaching head. Close to the surface (below $200 \mathrm{~m}$ ) there was a narrow zone of reverse flow $(\xi>0)$ that was probably frictionally driven. As seen in Fig. 8a, $\xi$ at this area reached $43 \times 10^{-2} \mathrm{~s}^{-1}$ at 12:50 UTC. Near surface, $\eta$ was also found to be significantly decreased (increased in absolute value) and was less than $-1.2 \times 10^{-1} \mathrm{~s}^{-1}$ (Fig. 8b). The evolution of such small scale but very intense vortices near the surface was strongly correlated with the production of dust at 12:50 UTC as shown in Fig. 8c. Propagation of the denser

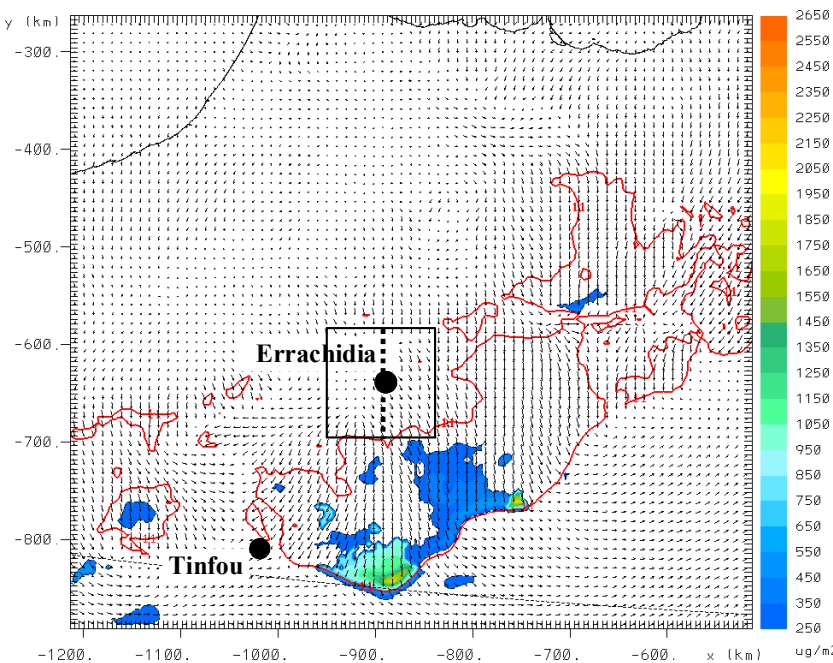

Fig. 4. Dust production (colored palette in $\mu \mathrm{g} \mathrm{m}^{-2}$ ) and wind arrows over the second $(2.4 \times 2.4 \mathrm{~km})$ model grid at 19:00 UTC on 31 May 2006. The red line represents the isotach of $11 \mathrm{~m} \mathrm{~s}^{-1}$. The black rectangular shows the location of the third grid and the vertical dashed line indicates the location of the cross sections of Fig. 5.

flow over lighter air led to gravitational instability at the head of the system and allowed the penetration of environmental flow at the base of the density current head in a way similar to the tank experiments described in Simpson (1972). Concentration of dust near the surface was doubled at 12:50 UTC indicating the mobilization of fresh dust particles along the frontal line.

Turbulent mixing was also increased inside the density current. The vertical profile of turbulent kinetic energy (TKE) in Fig. 8d indicates a mixing layer of about $2.5 \mathrm{~km}$ depth at 12:50 UTC with maximum TKE values along the boundary between the density current head and environmental flow. After the passage of the head the mixing depth was reduced to about $500 \mathrm{~m}$ as indicated by the TKE values between 13:00-13:20 UTC. After 13:00 UTC, increased turbulence associated with cloud development is also evident in Figure $8 \mathrm{~d}$ for a layer stretching from three to five $\mathrm{km}$ in the troposphere.

The structure of the density current flow and the uplifting of dust particles are also evident in the vertical cross-section from the fourth grid (Fig. 9a) at 18:50 UTC when the system was fully developed. For better understanding of the density current structure and propagation, the streamlines in this figure are represented in the front-relative frame of reference assuming an average propagating speed of $11 \mathrm{~m} \mathrm{~s}^{-1}$. This approach is useful for revealing small scale vortices within the propagating system. Due to surface friction, flow reversal and a returning undercurrent were found at the lower parts of the system as indicated by the anticlockwise rotation of the streamlines between $y=850 \mathrm{~km}$ and $y=855 \mathrm{~km}$ in Fig. 9a. A well-mixed dust layer was established, ranging 


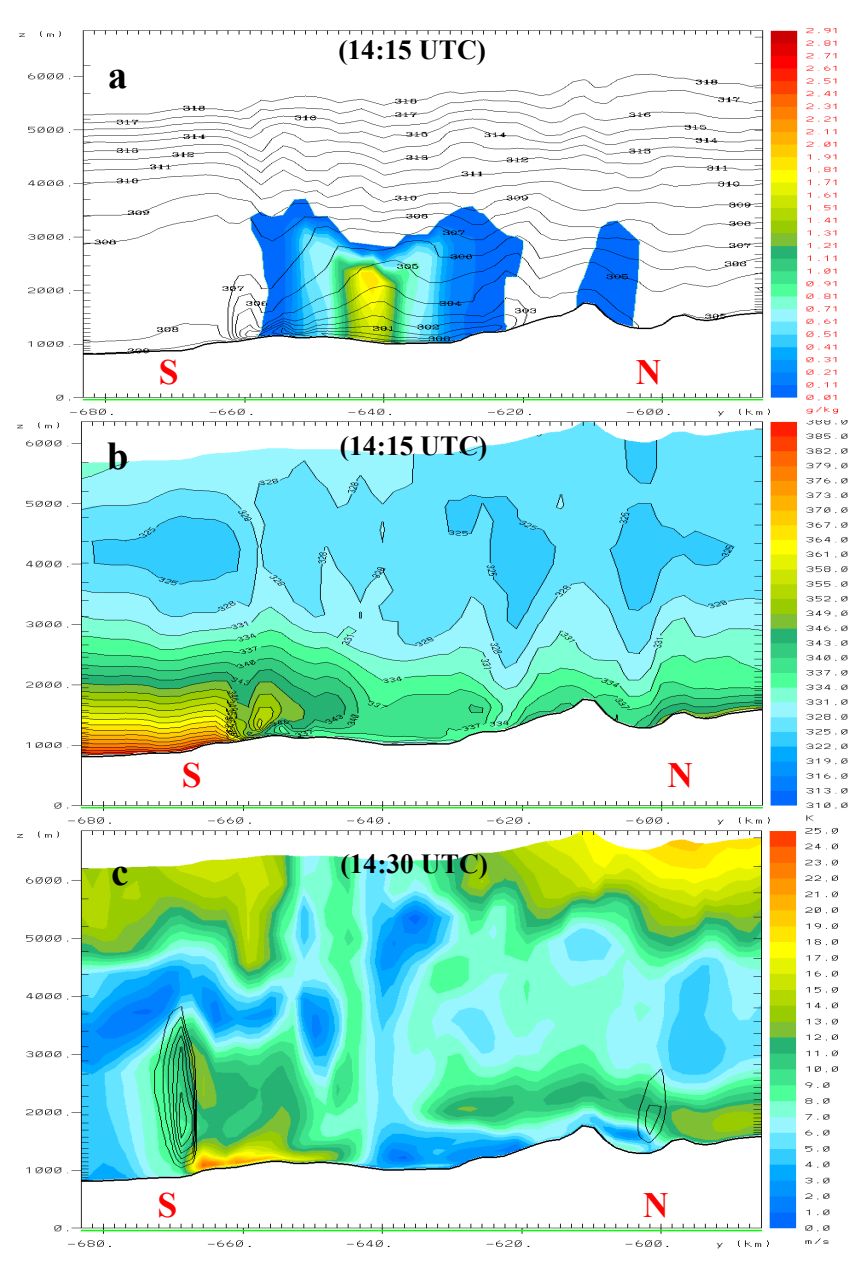

Fig. 5. North to south vertical cross-sections of: (a) Rain mixing ratio (colour palette in $\mathrm{g} \mathrm{kg}^{-1}$ ) and potential temperature (contour lines in K) at 14:15 UTC. (b) Equivalent potential temperature $\left(\theta_{\mathrm{e}}\right)$ in $\mathrm{K}$. (c) Horizontal wind speed (colour palette in $\mathrm{m} \mathrm{s}^{-1}$ ) and vertical updrafts (black line contours every $0.5 \mathrm{~m} \mathrm{~s}^{-1}$ ) at 14:30 UTC. The cross section is at $x=-889 \mathrm{~km}$.

in depth from $2 \mathrm{~km}$ at the frontal head to about $500 \mathrm{~m}$ at the rear of the system. The concentration of dust near the surface exceeded $3000 \mu \mathrm{g} \mathrm{m}^{-3}$. Inside the leading head and up to $1.5 \mathrm{~km}$ above ground the dust concentrations remained higher than $1500 \mathrm{\mu g} \mathrm{m}^{-3}$. Flow exchange between the density current and the free troposphere occurred mainly at the top of the frontal head where increased turbulence forced an amount of dust particles outside of the cool pool. Behind the leading head, a series of small scale vortices were formed along the interface between the semi-laminar and the disturbed flow due to increased vertical wind shear. These are Kelvin-Helmholtz billows and are evident in Fig. 9a centered at about $y=851 \mathrm{~km}$ and $y=837 \mathrm{~km}$. The horizontal extent of the disturbance varied from thirty up to forty kilometers and was accompanied by increased dust production as seen in Fig. 9b. The dust flux per model timestep reached a maximum of $440.19 \mu \mathrm{g} \mathrm{m}^{-2}$ at the area of reverse flow behind the leading head and remained between $290-360 \mu \mathrm{g} \mathrm{m}^{-2}$ for all the model grid points up to the tail of the density current. Outside of the system (in both front and rear parts) the production per model timestep was less than $50 \mu \mathrm{g} \mathrm{m}^{-2}$.

In an attempt to summarize the flow structure during a convectively driven dust episode, a schematic diagram has been constructed based on model findings as seen in Fig. 10. The reversal of flow $(\xi>0)$ behind the leading head that is evident in the NS cross section of Fig. 10a, is responsible for the formation of a returning undercurrent along the lowest layers of the system. When considering a WE plane perpendicular to the motion as seen in Fig. 10b, the flow at the lowest layers is towards the eastern side of the front $(\eta<0)$. This complex flow structure at the head of the density current, together with the development of turbulence and strong winds throughout the system extend, are responsible for the mobilization of dust. A possible explanation is that both the erosion of soil by bigger particles and the uplifting of mobilized dust are favored during such episodes. Most of the emitted particles are recirculated inside the density current and the concentration of dust is constantly increasing as long as the system propagates over dust sources. Ahead of the frontal line, the warmer environmental air is lifted upwards and intense turbulence is evident for a layer between one and two $\mathrm{km}$ height, associated also with cloud formation. Considerable amounts of dust are transported upwards inside the density current head. Due to turbulent mixing some particles are forced outside of the system into the free troposphere at the rear of the leading edge. Entrainment of preexisting airborne particles into the head of the density current may also occur due to uplifting and mixing along the frontal line updrafts. Turbulent mixing and recirculation of dust particles result in the formation of a propagating dust wall. Dust can elevate even higher than three kilometers in the troposphere and concentrations of more than $1000 \mu \mathrm{g} \mathrm{m}^{-3}$ may exist well above two km height.

\subsection{Changes in meteorology associated with the arrival of the density current}

The simulated density current approaches the station of Tinfou (lat: $30.24^{\circ} \mathrm{N}$, lon: $5.61^{\circ} \mathrm{W}$ ) - that is located at the western edge of the frontal line - at 18:00 UTC. The approaching of the front to Tinfou is indicated by the black arrow pointing at the leading front in Fig. 11. Convergence along the frontal line produces an arc cloud line. These clouds are evident at about $4-5 \mathrm{~km}$ height above the leading edge as indicated by the condensate mixing ratio contours in Fig. 11. The system is accompanied by a deeper precipitating cloud at a horizontal distance of about $50 \mathrm{~km}$ behind the front.

The arrival of the density current is indicated by the abrupt changes in several meteorological properties that were recorded at Tinfou station on 31 May 2006 (Fig. 12a-d). These observations were obtained during SAMUM campaign and are described in Knippertz et al. (2007). As seen 

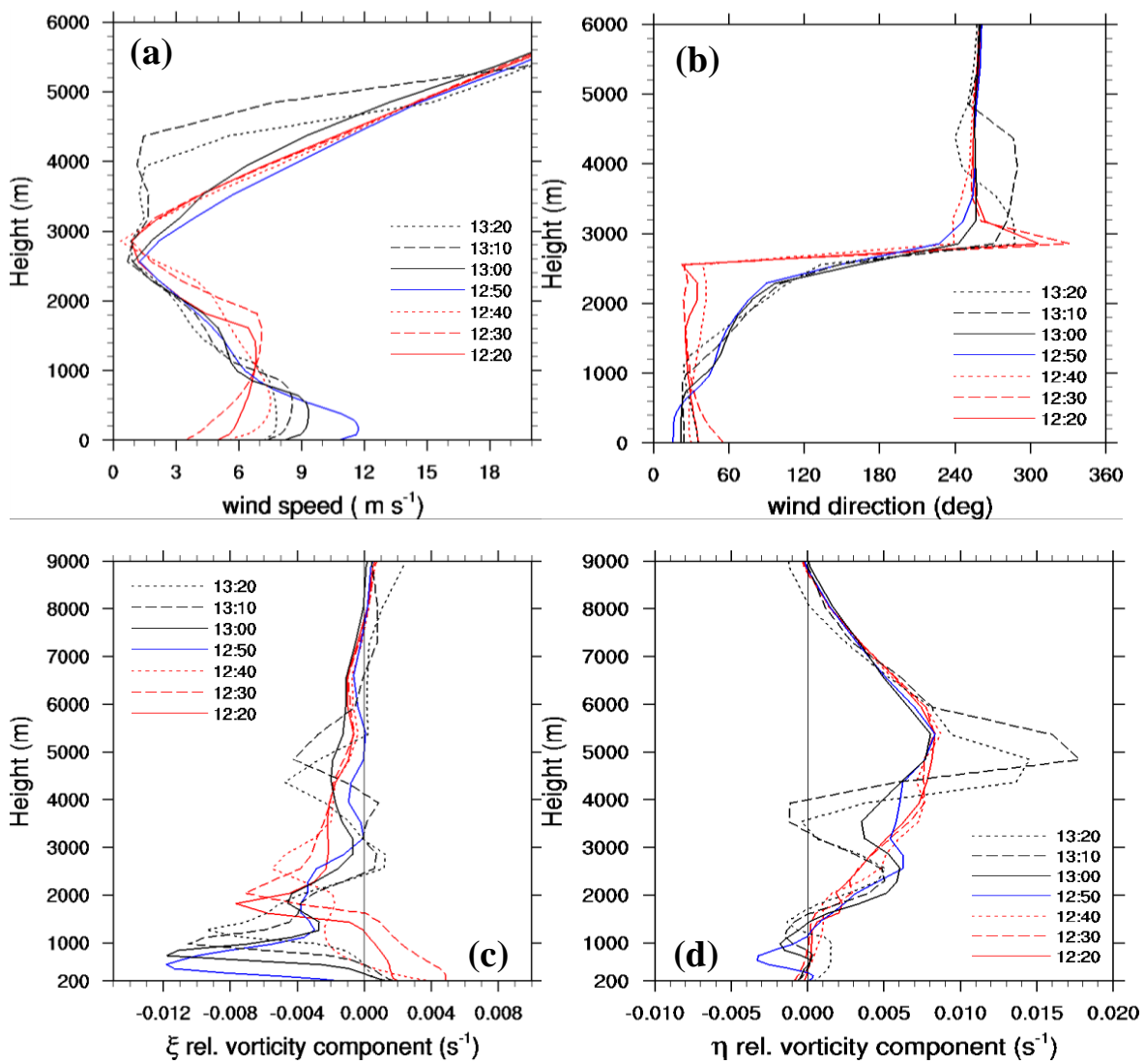

Fig. 6. Vertical profiles at lat $=31.81$, lon $=-4.39$ during the passage of the storm $(12: 20-13: 20)$ on 31 May 2006. (a) Wind speed (m $\mathrm{s}^{-1}$ ). (b) Wind direction (deg). (c) $\xi$ horizontal relative vorticity component $\left(\mathrm{s}^{-1}\right)$. (d) $\eta$ horizontal relative vorticity component $\left(\mathrm{s}^{-1}\right)$.

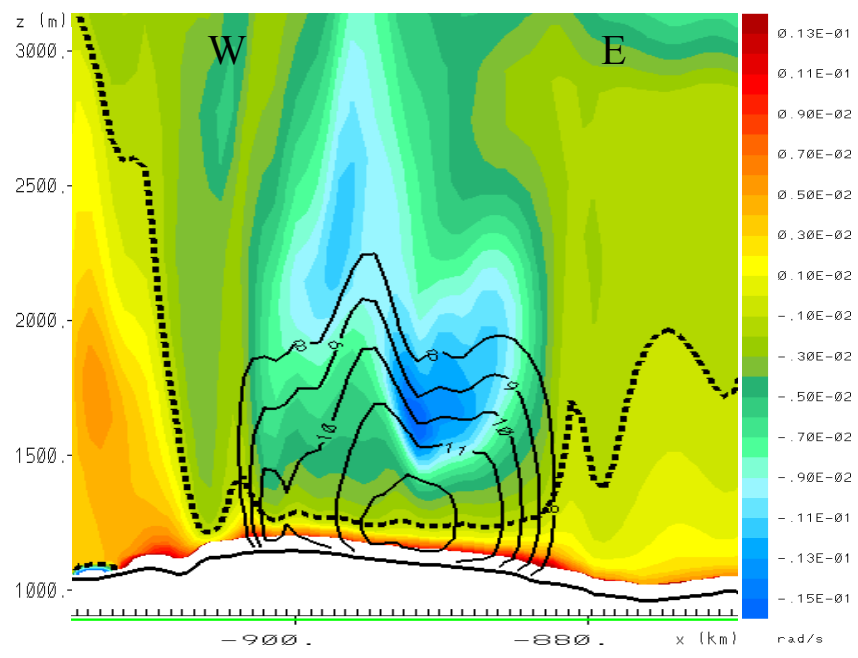

Fig. 7. Wind speed (solid black contours from $8-12 \mathrm{~m} \mathrm{~s}^{-1} \mathrm{ev}-$ ery $1 \mathrm{~m} \mathrm{~s}^{-1}$ ) and $\xi$ relative vorticity component (colour scale) at 12:50 UTC for a WE vertical cross-section at $y=-645 \mathrm{~km}$. The dashed black line represents $\xi=0$. in Fig. 12a, intrusion of the cooler air resulted in a sudden drop in ambient temperature that was reduced from $33^{\circ} \mathrm{C}$ at $18: 30 \mathrm{UTC}$ to $28^{\circ} \mathrm{C}$ at 19:00 UTC. The wind direction shifted from SW to NE at 18:30 UTC (Fig. 12b) and a jump of $7 \mathrm{~m} \mathrm{~s}^{-1}$ was recorded in wind speed between 18:30 19:00 UTC (Fig. 12c). Due to the arrival of the dust storm, the visibility at the station was dramatically reduced (Fig. 12d) and remained low during the next two hours.

Similar changes are found in the simulated meteorological properties but with a shift in time. The simulated density current arrived at 18:00 UTC, which is thirty minutes earlier than the observation. This difference can be probably attributed to improper representation of the surface characteristics (i.e. topography, roughness length etc.) within the second domain, due to the lower resolution. Smoothing of the topography in this grid by averaging within the grid box affects the representation of these features in the model and consequently the propagation speed of the density current. Modeling results for the station of Tinfou show a sharp increase of $8^{\circ} \mathrm{C}$ in dew point temperature (Fig. 12a) and a sharp increase of $7 \mathrm{~m} \mathrm{~s}^{-1}$ in wind speed at 18:00 UTC (Fig. 12c). Also, as seen in Fig. 12a, the modeled temperature is reduced from $32^{\circ} \mathrm{C}$ at $17: 45$ UTC to $26^{\circ} \mathrm{C}$ at $18: 30$ UTC while during 

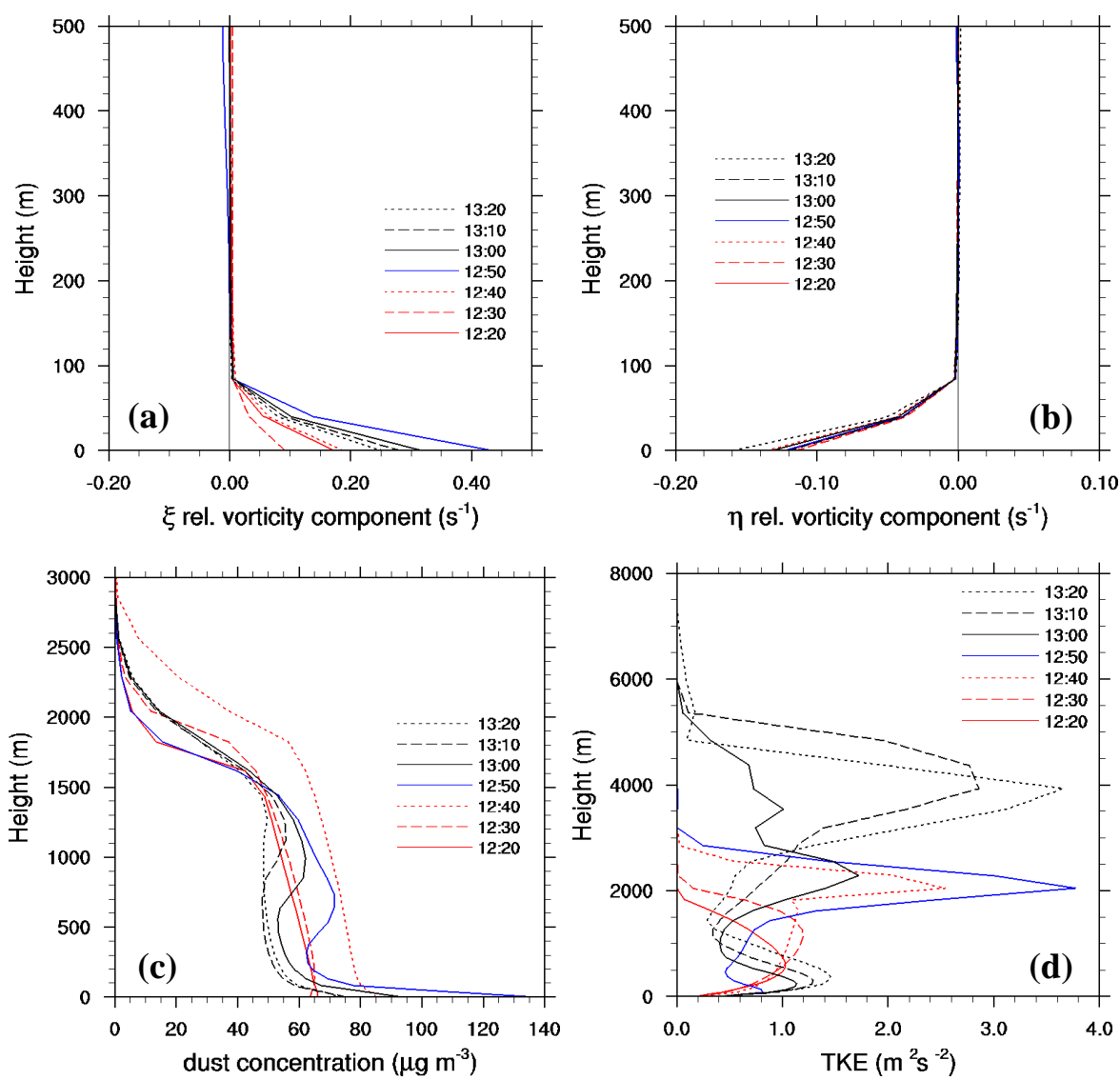

Fig. 8. Vertical profiles at lat $=31.81$, lon $=-4.39$ during the passage of the storm (12:20-13:20) on 31 May 2006. (a) $\xi$ horizontal relative

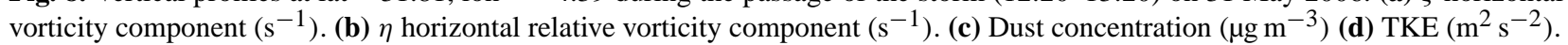

the same period the virtual temperature $\left(T_{\mathrm{v}}\right)$ is decreased by $3{ }^{\circ} \mathrm{C}$. The simulated wind direction shifts from WSW to NE at 17:30 UTC (Fig. 12b). Between 20:00-21:00 UTC the wind speed is increasing from 12 to $16 \mathrm{~m} \mathrm{~s}^{-1}$ indicating an overprediction during this period. The simulated visibility (Fig. 12d) is reducing during the dust storm. After 19:30 UTC the visibility is overpredicted and exceeds $20 \mathrm{~km}$. As seen also in Fig. 12d the recorded visibility in the station remained well below $10 \mathrm{~km}$ even after the passage of the system. The increased wind speed that persisted in the area resulted in local production of particles larger than $10 \mu \mathrm{m}$ (Kandler et al., 2008). These particles are not represented in the modeled dust distribution; therefore, this situation was not reproduced in the model.

The passage of the dust front over Tinfou is evident in Fig. 13, between 17:30 and 20:00 UTC. Especially between 18:00 and 19:00 UTC, the modeled concentration of dust close to the surface reaches $300 \mu \mathrm{g} \mathrm{m}^{-3}$ indicating the arrival of the system. After the passage of the main front, increased concentrations of dust (more than $250 \mu \mathrm{g} \mathrm{m}^{-3}$ ) are found aloft between 1 and $2.5 \mathrm{~km}$ height. This "dust cloud" is formed from particles that are forced outside of the density current due to increased turbulence at the top of the prop- agating head and also from the uplifting of prefrontal airborne dust. The prevailing SW winds at this station during the previous hours (between 14:00-17:00 UTC), resulted in transportation of dust from the areas south of Tinfou and as seen in Fig. 13 a dust background of about $100 \mu \mathrm{g} \mathrm{m}^{-3}$ had already been established at the area before the approaching of the system. The abrupt increase in dust concentration after 17:30 UTC is attributed to particles that originated from dust sources north of Tinfou and were transported along the density current frontal line.

\subsection{Effects of model grid spacing on resolving the system}

In order to examine the significance of the model grid resolution on the ability to resolve these processes, six more runs have been performed for the same event (see Table 1): first, the model was set up with exactly the same configuration as the control run but only the two outer grids were enabled (i.e. the inner $800 \times 800 \mathrm{~m}$ grids were omitted). Most mesoscale features (i.e. convection, density current generation and dust transportation) were reproduced on the two-grid run in a similar way to the three-grid run but with weaker gradients. The 


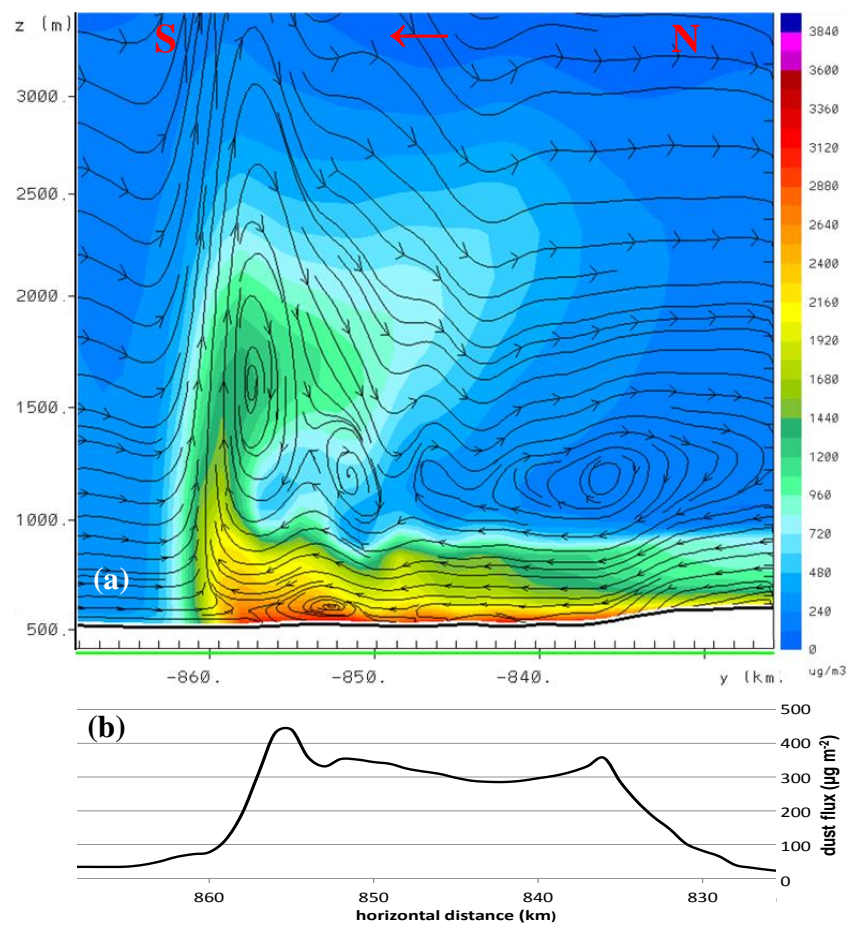

Fig. 9. (a) Dust concentration (color scale in $\mu \mathrm{g} \mathrm{m}^{-3}$ ) and streamlines at 18:50 UTC for a reference frame relative to the propagating speed. The location of the cross section is at $x=-898$. The direction of the motion is from North to South as illustrated with the red arrow on top of the figure. (b) Dust flux ( $\mu \mathrm{g} \mathrm{m}^{-2} /$ model timestep) at each model grid point along the same cross section.
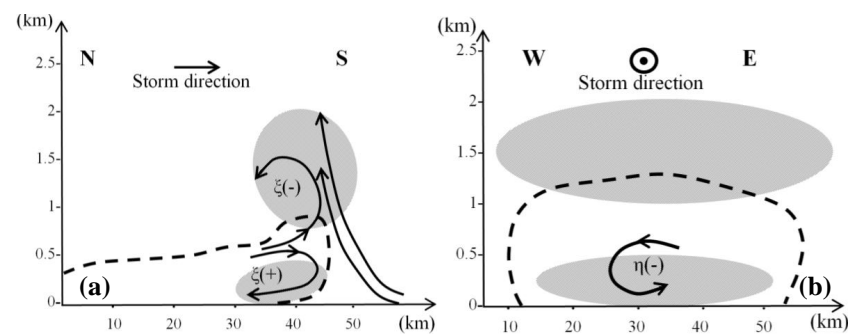

Fig. 10. Schematic representation of the flow structure during the cool pool intrusion. The dashed line indicates the boundary of the density current. Shaded figures indicate areas of increased turbulence. (a) Considering a NS vertical plane parallel to the axis of motion, the flow is rotating clockwise close to the surface $(\xi+)$ and anti-clockwise above $(\xi-)$. (b) Considering a WE vertical plane perpendicular to the motion the flow is rotating anti-clockwise $(\eta-)$. The storm direction in this figure is towards the reader.

resolution of the second model grid $(2.4 \times 2.4 \mathrm{~km})$ was sufficient for reproducing moisture processes and convection at this scale. Minor differences between the two-grid and four-grid runs were found, mainly regarding the dust concentrations at the remote station of Tinfou. For example, the maximum dust concentration at $925 \mathrm{mb}$ over Tinfou station was $328 \mu \mathrm{g} \mathrm{m}^{-3}$ for the four-grid run and $271 \mu \mathrm{g} \mathrm{m}{ }^{-3}$ for

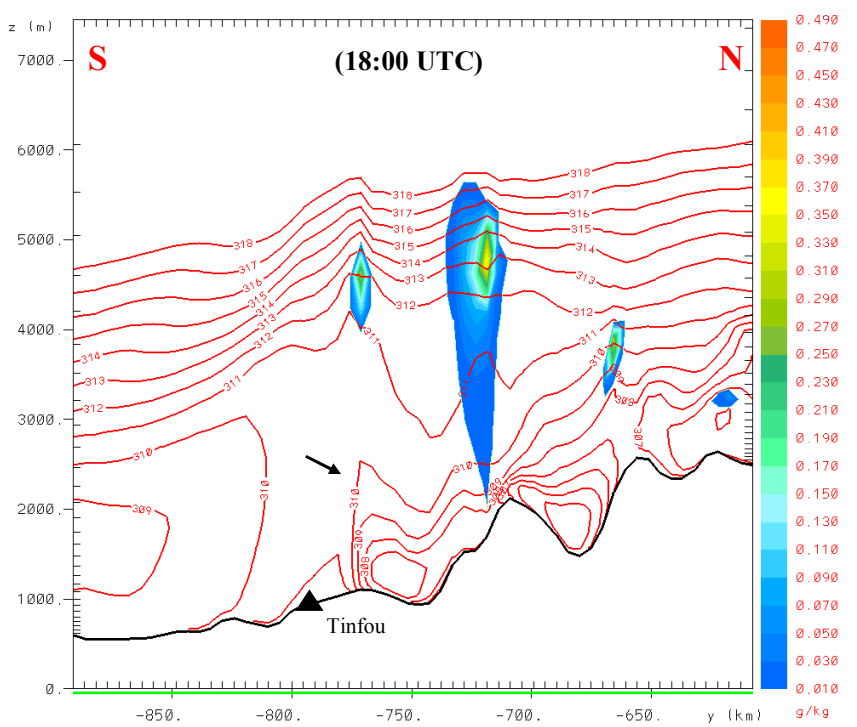

Fig. 11. North to south vertical cross-section of total condensates mixing ratio (colour scale in $\mathrm{g} \mathrm{kg}^{-1}$ ) and potential temperature (red contour lines in K) at 18:00 UTC. The deepening of isentropic layers (indicated with a black arrow) indicates the approaching of the density current at the station of Tinfou (denoted with a black triangle). The cross section is at $x=-1022 \mathrm{~km}$.

the two-grid run. Then, the same run was performed using a single outer grid of $(24 \times 24 \mathrm{~km})$ to cover the entire modeling domain. During this single grid run, despite the fact that the convective precipitation event was still reproduced, the model failed to resolve the generation of the density current and consequently the associated dust storm. Subsequent runs using a single grid of $16 \times 16 \mathrm{~km}$ and one of $12 \times 12 \mathrm{~km}$ covering the same area of the outer grid indicated that the density current and dust mechanisms were poorly if at all reproduced. This is something expected since the density currents are rather meso- $\gamma$ or even meso- $\beta$ scale features with strong non-hydrostatic features that are normally resolved with a grid increment of $\sim 7-8 \mathrm{~km}$ or smaller. Replacing the intermediate $2.4 \times 2.4 \mathrm{~km}$ grid with an equivalent of $4.8 \times 4.8 \mathrm{~km}$ resolution, the reproduction of the non-hydrostatic components and the main features of the phenomena were still resolved in a similar way. Finally, the use of an intermediate grid of $8 \times 8 \mathrm{~km}$ resolution resulted in acceptable description of convective activity but the intensity of the density current was weaker and dust production was underestimated. The system in this case arrived at Tinfou at 20:00 UTC, which is about $1.5 \mathrm{~h}$ later than observed and the maximum dust concentration at $925 \mathrm{mb}$ was $216 \mu \mathrm{g} \mathrm{m}^{-3}$.

\subsection{Investigation of the possible dust effects on convection}

Dust particles are expected to be hydrophobic near the sources so their ability to activate as cloud droplets is limited. 

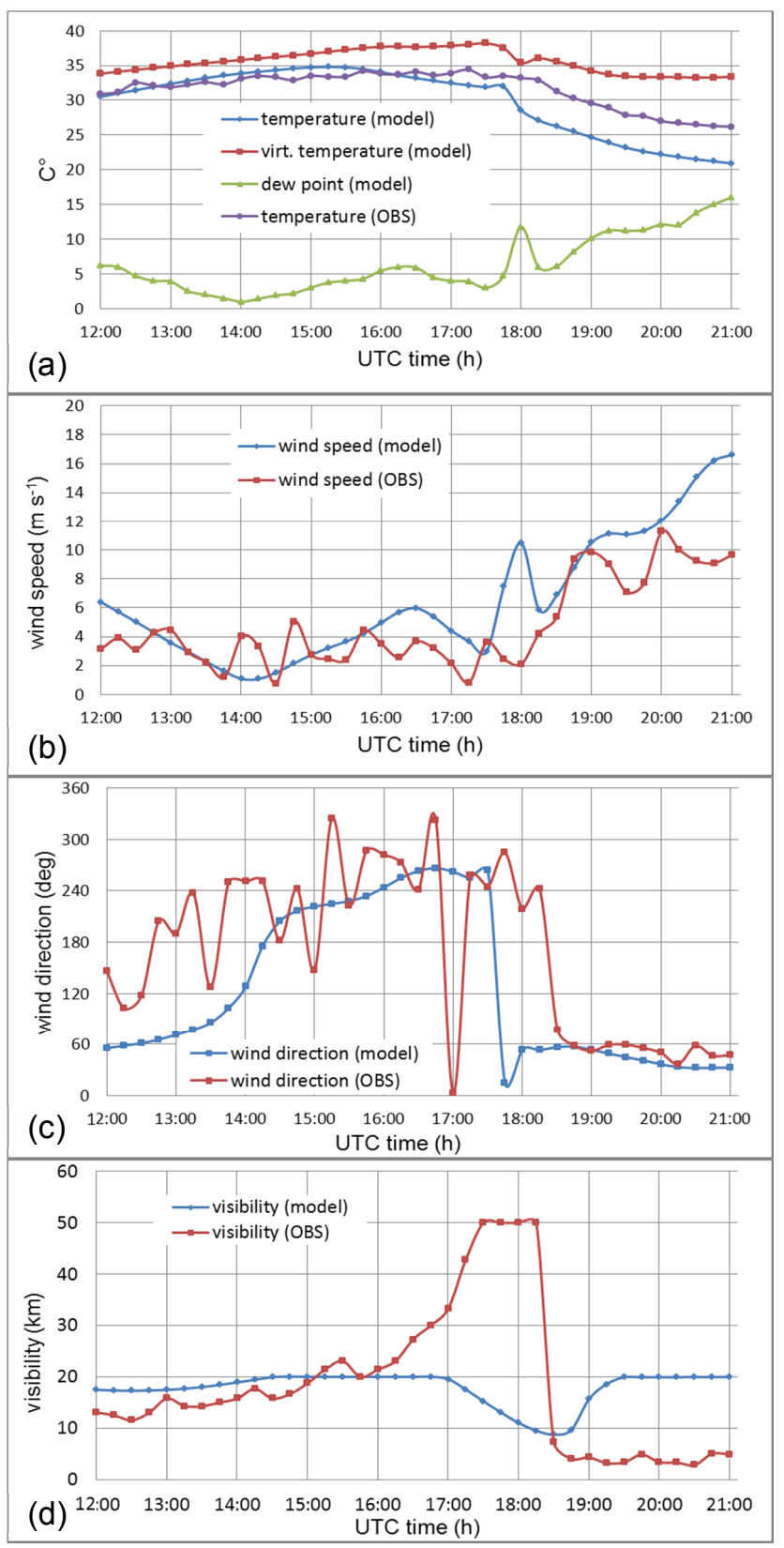

Fig. 12. Time series of observations and model results at Tinfou station. (a) Temperature, dew point and virtual temperature $\left({ }^{\circ} \mathrm{C}\right)$ (b) Wind direction (deg) (c) Wind speed $\left(\mathrm{m} \mathrm{s}^{-1}\right)$ and (d) Visibility (km).

However, in increased moisture conditions some of these particles may form gigantic cloud condensation nuclei (GCCN). Dust is also known to act as effective IN. In order to investigate the possible role of these particles on the generation and evolution of the cool pool, four more simulations were performed. The model configuration was the same as described in Sect. 2. Dust particles in this series of runs were treated as predictive quantities for the activation of cloud

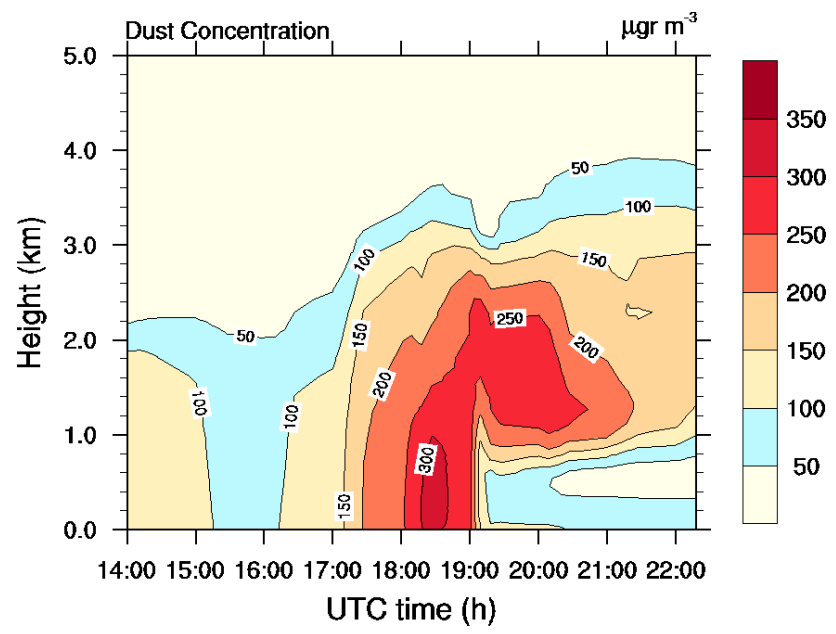

Fig. 13. Time evolution of dust concentration $\left(\mu \mathrm{g} \mathrm{m}^{-3}\right)$ over Tinfou station on 31 May 2006.

Table 1. Summary of sensitivity tests for seven model configurations.

\begin{tabular}{llll}
\hline $\begin{array}{l}\text { Number of } \\
\text { grids }\end{array}$ & $\begin{array}{l}\text { Resolution } \\
(\mathrm{km} \times \mathrm{km})\end{array}$ & Convection & $\begin{array}{l}\text { Density } \\
\text { current }\end{array}$ \\
\hline One & $24 \times 24$ & YES & NO \\
One & $16 \times 16$ & YES & NO \\
One & $12 \times 12$ & YES & NO \\
Two & grid1: $24 \times 24$ & YES & YES \\
& grid2: $4.8 \times 4.8$ & & \\
Two & grid1: $24 \times 24$ & YES & YES \\
& grid2: $8 \times 8$ & & \\
Two & grid1: $12 \times 12$ & YES & YES \\
& grid2: $2.4 \times 2.4$ & & \\
Four & grid1: $12 \times 12$ & YES & YES \\
& grid2: $2.4 \times 2.4$ & & \\
grid3,4: & & \\
& $0.8 \times 0.8$ & & \\
\hline
\end{tabular}

droplet formation. For the first three runs, the portions of dust that were assumed to be efficient $\mathrm{CCN}$ were $1 \%, 10 \%$ and $20 \%$, respectively. During the fourth run, $10 \%$ of dust particles were assumed to be hygroscopic, enabling also the ability for all dust particles to act as effective IN. For the cloud droplet activation processes the FN parameterization was used (Fountoukis and Nenes, 2005). Contribution of dust in ice formation was described with the scheme of Barahona and Nenes (2009). This scheme has been adopted in the model to account for the effects of prognostic dust particles on ice processes.

Minor changes on the rainfall rate and the spatial distribution of precipitation were found between the different scenarios of microphysical activity. However, the structure and the characteristics of the outflow boundary were almost identical and there was no remarkable difference regarding 
the properties of the density current and the production and transportation of dust. These results indicate that moisture properties and atmospheric dynamics are the major factors for the development of these systems. The effect of dust particles on cloud microphysics was not found to be important for triggering the density current mechanism.

\section{Summary and conclusion}

The formation and propagation of density currents over desert areas is an additional source of dust and needs to be treated accordingly in atmospheric-dust modeling. For this reason, an integrated high resolution (cloud resolving) model that includes direct coupling of air-quality and atmospheric processes has been developed. The model was used for the explicit resolving of local scale features such as cool pools and density currents that are responsible for the mobilization of dust particles. Online dust parameterization allowed the description of the main physical processes involved in the generation of dust episodes in these areas. The detailed analysis of a representative case study over NW Africa as well as a number of other simulated similar cases in Africa and the Middle East suggests a common structure of these systems. Their main properties can be summarized as follows:

- "Haboob" type of density currents are relatively shallow with depths ranging from $0.5 \mathrm{~km}$ at the rear of the head to approximately $2 \mathrm{~km}$ along the leading edge. The frontal extend can be at the order of hundreds of kilometers while their life time is ranging between 2 to $12 \mathrm{~h}$ depending on their size.

- The propagating front is arc-shaped rather than linear as it is usually found in mid-latitude squall lines. The reason is that the down pouring of cool air masses splashes and spreads around in a rather cyclical shape. Depending on the environmental conditions and surface characteristics these downdrafts may evolve to density currents towards one or more directions.

- The flow structure of the density current is similar to the one described during idealized tank experiments as reported in earlier studies. A reversal of flow is evident near the surface just behind the leading head and a flow discontinuity area is defining the upper boundary of the density current body.

- Dust productivity is enhanced mainly due to increased turbulence near the surface and the area of maximum dust production is collocated with the area of reverse flow behind the leading edge.

- The wind speed behind the gust front is higher than the speed of propagation and the uplifted particles are transported towards the leading head. As the system propagates, the concentration of dust inside the density current head is constantly increasing reaching values of a few thousand $\mu \mathrm{g} \mathrm{m}^{-3}$. Sand particles of tens of $\mu \mathrm{m}$ in radius are mixed with smaller dust particles. Sand particles settle quickly due to gravitational forcing.

- Due to the capping at the upper boundary of the density current, a large amount of the produced dust particles are trapped inside the system and injection of dust into the free troposphere occurs mainly in three ways:

1. When the system moves towards areas with preexisting dust particles, these are uplifted through the prefrontal updrafts above the density current body.

2. Turbulent mixing along the dust wall results in entrainment of dust particles in the strong updrafts and their transport in higher layers of the lower troposphere.

3. During daytime, surface heating leads in erosion of the cool pool and therefore the quick increase of the mixing layer at the rear of the system. In this way, the mobilized dust is uplifted to higher layers.

- The primary removal mechanisms are the gravitational settling (particularly the larger sand particles) and the scavenging from the rain droplets (particularly during the initial stages of development).

The density currents are systems with strong pressure gradients where the non-hydrostatic components of forcing are very important. Therefore, the horizontal model resolution must be higher than $7-8 \mathrm{~km}$. For detailed gradient description there is a need of even higher resolution of $\sim 1 \mathrm{~km}$. Sensitivity of convection towards dust-CCN activation was found to be limited and the evolution of the cool pool was in general dynamically driven. Similar dust storms that are developed south of the Intertropical Convergence Zone (ITCZ) due to Mesoscale Convective Systems (MCS) outflows or due to the NE intrusion of the West African monsoon, contribute to dust export from West Africa. The proximity of these systems to the discontinuity zone allows the capturing of the elevated particles by the tropical easterlies. In this way dust is transported towards the Atlantic. In contrary, it seems that the haboobs that are developed north of the ITCZ do not directly contribute to the export of Saharan dust towards the Atlantic or towards the Mediterranean. The development of a shallow mixing layer inhibits vertical mixing of dust and most of these systems decay before they reach the African coast. Nevertheless, a considerable portion of the particles that are released from these systems into higher tropospheric layers are eligible for long range transport. These particles are transferred along with the mesoscale flow structures and contribute to the dust load occurring during Saharan dust outbreaks. In local scale, haboobs are very violent and hazardous phenomena with significant implications to weather conditions and human activities. Appropriate treatment of these systems as additional dust sources in atmospheric models is necessary for improving the representation 
of dust emissions. This is an important step for reducing the uncertainty in direct and indirect forcing of dust in the atmosphere.

Acknowledgements. This work has been carried out at the framework of the European Union 6th Framework Program CIRCE IP, contract\# 036961 and EUROCONTROL Research Studentship Agreement no CO6/22048ST. The authors would like to thank Konrad Kandler (Technische Universität Darmstadt) for providing the Tinfou station data.

Edited by: X. Querol

\section{References}

Barahona, D. and Nenes, A.: Parameterizing the competition between homogeneous and heterogeneous freezing in ice cloud formation - polydisperse ice nuclei, Atmos. Chem. Phys., 9, 59335948, doi:10.5194/acp-9-5933-2009, 2009.

Bou Karam, D., Flamant, C., Knippertz, P., Reitebuch, O., Pelon, J., Chong, M., and Dabas, A: Dust emissions over the Sahel associated with the West African Monsoon inter-tropical discontinuity region: a representative case study, Q. J. Roy. Meteor. Soc., 134, 621-634, 2008.

Cakmur, R. V., Miller, R. L., and Torres, O.: Incorporating the effect of small-scale circulations upon dust emission in an atmospheric general circulation model, J. Geophys. Res., 109, D07201, doi:10.1029/2003JD004067, 2004.

Carbone, R. E.: A severe frontal rainband. Part I: Stormwide hydrodynamic structure, J. Atmos. Sci., 39, 258-279, 1981.

Carbone, R. E.: A Severe Frontal Rainband. Part II: Tornado Parent Vortex Circulation, J. Atmos. Sci., 40, 2639-2654, 1983.

Chen, W. and Fryrear, D.: Sedimentary characteristics of a haboob dust storm, Atmos. Res., 61, 75-85, 2002.

Chimonas, G. and Kallos, G.: Flow Dynamics and Stability in a Severe Rainband, J. Atmos. Sci., 43, 1505-1516, 1985.

Cotton W. R., Pielke Sr., R. A., Walko, R. L., Liston, G. E., Tremback, C. J., Jiang, H., McAnelly, R. L., Harrington, J. Y., Nicholls, M. E., Carrio, G. G., and McFadden, J. P.: RAMS 2001: Current status and future directions, Meteor. Atmos. Phys., 82, 5-29, 2003.

Emmel, C., Knippertz, P., and Schulz, O.: Climatology of convective density currents in the southern foothills of the Atlas Mountains, J. Geophys. Res., 115, D11115, doi:10.1029/2009JD012863, 2010.

Fécan, F., Marticorena, B., and Bergametti, G.: Parametrization of the increase of the aeolian erosion threshold wind friction velocity due to soil moisture for arid and semi-arid areas, Ann. Geophys., 17, 149-157, doi:10.1007/s00585-999-0149-7, 1999.

Fountoukis, C. and Nenes, A.: Continued Development of a Cloud Droplet Formation Parameterization for Global Climate Models, J. Geophys. Res., 110, D11212, doi:10.1029/2004JD005591, 2005.

Givati, A. and Rosenfeld, D.: Quantifying precipitation suppression due to air pollution, J. Appl. Meteor., 43, 1038-1056, 2004.

Hastenrath, S.: Climate Dynamics of the Tropics, Kluwer Academic Publishers, Dordrecht, Netherlands, 488 pp., 1991.
Heinold, B., Helmert, J., Hellmuth, O., Wolke, R., Ansmann, A., Marticorena, B., Laurent, B., and Tegen, I.: Regional Modeling of Saharan Dust Events using LM-MUSCAT: Model Description and Case Studies, J. Geophys. Res., 112, D11204, doi:10.1029/2006JD007443, 2007.

Iacono, M. J., Mlawer, E. J., Clough, S. A. and Morcrette, J. J.: Impact of an improved longwave radiation model, RRTM, on the energy budget and thermodynamic properties of the NCAR Community Climate Model, CCM3, J. Geophys. Res., 105, 1487314890, 2000.

IPCC: Changes in atmospheric constituents and radiative forcing: Climate change: the physical science basis, Cambridge University Press, New York, USA, and Cambridge, UK, 2007.

Kain, J. S. and Fritsch, J. M.: Convective parameterization for mesoscale models: The Kain-Fritsch scheme. The representation of cumulus convection in numerical models, Meteor. Monogr., No. 24, Amer. Meteor. Soc., 165-170, 1993.

Kandler, K., Schütz, L., Deutscher, C., Ebert, M., Hofmann, H., Jackel, S., Jaenicke, R., Knippertz, P., Lieke, K., Massling, A., Petzold, A., Schladitz, A., Weinzierl, B., Wiedensohler, A., Zorn, S., and Weinbruch, S.: Size distribution, mass concentration, chemical and mineralogical composition, and derived optical parameters of the boundary layer aerosol at Tinfou, Morocco, during SAMUM 2006, Tellus, 61B, 32-50, doi:10.1111/j.16000889.2008.00385.x, 2008.

Knippertz, P., Christoph, M., and Speth, P.: Long-term precipitation variability in Morocco and the link to the large-scale circulation in recent and future climates, Meteorol. Atmos. Phys., 83, 67-88, 2003.

Knippertz, P., Deutscher, C., Kandler, K., Muller, T., Schulz, O., and Schutz L.: Dust mobilization due to density currents in the Atlas region. Observations from the Saharan Mineral Dust Experiment 2006 field campaign, J. Geophys. Res., 112, D21109, doi:10.1029/2007JD008774, 2007.

Knippertz, P., Trentmann, J., and Seifert, A.: High-resolution simulations of convective cool pools over the northwestern Sahara, J. Geophys. Res., 114, D08110, doi:10.1029/2008JD011271, 2009.

Lawson, T.: Haboob structure at Khartoum, Weather, 26, 105-112, 1971.

Levin, Z., Ganor, E., and Gladstein, V.: The effects of desert particles coated with sulfate on rain formation in the eastern Mediterranean, J. Appl. Meteorol., 35, 1511-1523, 1996.

Marsham, J. H., Knippertz, P., Dixon, N. S., Parker, D. J., and Lister, G. M. S.: The importance of the representation of deep convection for modeled dust-generating winds over West Africa during summer, Geophys. Res. Lett., 38, L16803, doi:10.1029/2011GL048368, 2011.

Marticorena, B. and Bergametti, G.: Modeling the atmospheric dust cycle: 1 . Design of a soil derived dust emission scheme, J. Geophys. Res., 100, 16415-16430, 1995.

Marticorena, B., Bergametti, G., Aumont, B., Callot, Y., N’Doumé, C., and Legrand, M.: Modeling the atmospheric dust cycle, 2, Simulation of Saharan dust sources, J. Geophys. Res., 102, 4387 4404, 1997.

Marticorena, B., Chatenet, B., Rajot, J. L., Traoré, S., Coulibaly, M., Diallo, A., Koné, I., Maman, A., NDiaye, T., and Zakou, A.: Temporal variability of mineral dust concentrations over West Africa: analyses of a pluriannual monitoring from the AMMA Sahelian Dust Transect, Atmos. Chem. Phys., 10, 8899-8915, 
doi:10.5194/acp-10-8899-2010, 2010.

Membery, D.: A gravity-wave haboob?, Weather, 40, 214-221, 1985.

Meyers, M. P., Walko, R. L., Harrington, J. Y., and Cotton, W. R: New RAMS cloud microphysics parameterization. Part II: The two-moment scheme, Atmos. Res., 45, 3-39, 1997.

Miller, S. D., Kuciauskas, A. P., Liu, M., Ji, Q., Reid, J. S., Breed, D. W., Walker, A. L., and Mandoos, A. A.: Haboob dust storms of the southern Arabian Peninsula, J. Geophys. Res., 113, D01202, doi:10.1029/2007JD008550,2008

Mlawer, E. J., Taubman, S. J., Brown, P. D., Iacono, M. J., and Clough, S. A.: Radiative transfer for inhomogeneous atmospheres: RRTM, a validated correlated-k model for the longwave, J. Geophys. Res., 102, 16663-16682, 1997.

Myhre, G., Grini, A., Haywood, J. M., Stordal, F., Chatenet, B., Tanr, D., Sundet, J. K., and Isaksen, I. S. A.: Modelling the radiative impact of mineral dust aerosol during the Saharan Dust Experiment (SHADE) campaign, J. Geophys. Res., 108, 8579, doi:10.1029/2002JD002566, 2003.

Pielke, R. A., Cotton, W. R., Walko, R. L., Tremback, C. J., Lyons, W. A., Grasso, L. D., Nicholls, M. E., Moran, M. D., Wesley, D. A., Lee, T. J., and Copeland, J. H.: A comprehensive meteorological modeling system - RAMS, Meteorol. Atmos. Phys., 49, 69-91, 1992.

Ramanathan, V., Ramana, M. V., Roberts, G., Kim, G., Corrigan, D., Chung, C., and Winker, D.: Warming trends in Asia amplified by brown cloud solar absorption, Nature, 448, 575-578, 2007.

Reinfried, F., Tegen, I., Heinold, B., Hellmuth, O., Schepanski, K., Cubasch, U., Hübener, H., and Knippertz, P.: Simulations of convectively-driven density currents in the Atlas Region using a regional model: Impacts on dust emission and sensitivity to horizontal resolution and convection schemes, J. Geophys. Res.Atmos., 114, D08127, doi:10.1029/2008JD010844, 2009.

Schepanski, K., Tegen, I., Todd, M. C., Heinold, B., Bönisch, G., Laurent, B., and Macke, A.: Meteorological processes forcing Saharan dust emission inferred from MSG-SEVIRI observations of subdaily dust source activation and numerical models, J. Geophys. Res., 114, D10201, doi:10.1029/2008JD010325, 2009.

Schmetz, J. P., Pili, P., Tjemkes, S., Just, D., Kerkmann, J., Rota, S., and Ratier, A.: An Introduction to Meteosat Second Generation (MSG), B. Am. Meteorol. Soc., 83, 977-992, 2002.

Seigel, R. B. and van den Heever, S. C.: Dust Lofting and Ingestion by Supercell Storms, J. Atmos. Sci., 69, 1453-1473, doi:10.1175/JAS-D-11-0222.1, 2012.
Seinfeld, J. H. and Pandis, S. N.: Atmospheric Chemistry and Physics: From Air Pollution to Climate Change, J. Wiley, New York, 1998.

Seinfeld, J. H., Carmichael, G. R., Arimoto, R., Conant, W. C., Brechtel, F. J., Bates, T. S., Cahill, T. A., Clarke, A. D., Doherty, S. J., Flatau, P. J., Huebert, B. J., Kim, J., Markowicz, K. M., Quinn, P. K., Russell, L. M., Russell, P. B., Shimizu, A., Shinozuka, Y., Song, C. H., Tang, Y., Uno, I., Vogelmann, A. M., Weber, R. J., Woo, J.-H., and Zhang, X. Y.: ACE-ASIA regional climate and Atmospheric chemical effects of Asian dust and pollution, B. Am. Meteorol. Soc., 85, 367-380, 2004.

Simpson, J. E.: Effects of the lower boundary on the head of a gravity current, J. Fluid Mech., 53, 759-768, 1972.

Solomos, S., Kallos, G., Kushta, J., Astitha, M., Tremback, C., Nenes, A., and Levin, Z.: An integrated modeling study on the effects of mineral dust and sea salt particles on clouds and precipitation, Atmos. Chem. Phys., 11, 873-892, doi:10.5194/acp11-873-2011, 2011

Spyrou, C., Mitsakou, C., Kallos, G., Louka, P., and Vlastou, G.: An improved limited-area model for describing the dust cycle in the atmosphere, J. Geophys. Res., 115, D17211, doi:10.1029/2009JD013682, 2010.

Steppeler, J., Doms, G., Schattler, U., Bitzer, H. W., Gassman, A., Damrath, U., and Gregoric, G.: Meso-gamma scale forecasts using the nonhydrostatic model LM., Meteorol. Atmos. Phys., 82, 75-96, 2003.

Sutton, L.: Haboobs, Q. J. Roy. Meteor. Soc., 51, 25-30, 1925.

Takemi, T.: Explicit simulations of convective-scale transport of mineral dust in severe convective weather, J. Meteorol. Soc. Jpn., 83A, 187-203, 2005.

Tegen, I., Werner, M., Harrison, S. P., and Kohfeld, K. E.: Relative importance of climate and land use in determining present and future global soil dust emission, Geophys. Res. Lett., 31, L05105, doi:10.1029/2003GL019216, 2004.

Von Karman, T.: The engineer grapples with nonlinear problems, B. Am. Math. Soc., 46, 615-683, 1940.

Zender, C. S., Bian, H., and Newman, D.: Mineral Dust Entrainment and Deposition (DEAD) model: Description and 1990s dust climatology, J. Geophys. Res., 108, 4416, doi:10.1029/2002JD002775, 2003. 